\title{
Euthanasia - The Choice between the Right to Life and Human Dignity PhD Candidate Oljana Hoxhaj
}

\author{
University of "Isamil Qemali" Vlora, Faculty of Human Sciences, Department of Law \\ oljana.hoxhaj@gmail.com \\ MSC. Suela Hoxhaj \\ University of "Isamil Qemali" Vlora, Faculty of Human Sciences, Department of Law \\ ela.hoxhaj@gmail.com
}

Doi:10.5901/ajis.2014.v3n6p279

\begin{abstract}
Euthanasia is a modern concept in Albanian society, characterized by complexity and legal vacuum. Our legislation protects the life right and is in full compliance with second Article of the European Convention of Human Rights, but does not provide and is not sanctioned in any section, the right of death. Discussions arising in this context, are related to whether euthanasia should be defined as a criminal or as non-crime action, that brings the respect of human dignity and therefore the protection and promotion of a basic constitutional principle. Theoretical discussions have not been lacking in treating this important issue, which has an impact not only in legal field, but also in the social, medical and religious. Through this paper, i intend to present an overview of the Albanian and European legislation of euthanasia. The question in many legal systems, is if life right should prevail , in conditions where a person has no more dignity, or must be granted the right to voluntary choose death, as a worthy act.
\end{abstract}

Keywords: human dignity, legal vacuum, elections, legislation

\section{The Life Right in the Albanian Legislation and in Article 2 of the European Convention}

The life right, is the first fundamental human right, whose existence, is the condition for enjoyment of all other rights. It is classified in rights category, closely related to human as a natural being, with dignity and his existence. The life right, located on top of the catalog of human rights, in Albania's constitution, reinforces the fact that this is not a right given by state, legislator or government. Life right, and a range of other rights, are natural rights born with citizens. Our Constitution states: Everyone's right to life shall be protected by law.(Article 21 of Albanian Constitution). This clause, express the guarantee of the right to life, noting the importance that presents its defense. State shall take all necessary measures, to monitor and control the observance of the constitutional right to life. In this context, the legislator adopts laws that ensure the protection of life.( Omari, Anastasi, 2008, p 122) Albanian Constitution has moved in the same direction with the European Convention of Human Rights, in sanctioning of the life right.

1. The right of everyone to live, is protected by law. No one shall be deprived intentionally of life, except when the court gives a death decision, for a crime punishable by law with this sentence.

2. Life is not considered deprived in contravention of this article, when this deprivation comes from using force, which is absolutely necessary:

a. In defense of any person from unlawful violence;

b. To make a lawful arrest or to prevent the escape of a person who is lawfully detained;

c. To oppose in accordance with the law, a riot or insurrection. (Article 2 of the European Convention on Human Rights)

The right to life is certainly one of the fundamental human rights. After noted this, it is important to note that neither Article 2 that declares this right, nor Protocols No. 6 and 13, that require the repeal of death sentence, are not intended to defend life unconditionally, or to guarantee a certain quality of life. Instead, these provisions aim to protect the person against every arbitrary opportunity of the state (McCann and others $\vee$ United Kingdom,1995) to cause death or murder that may result from using force by a private person. (Ergi v Turkey ,1998) Protection includes both substantive and procedural element. (Gomien, 2005, p 15-16) 


\section{The Right to Die - Euthanasia}

The right to die is closely related to life right, therefore it's a very complex and delicate right to handle. Its complexity is noticed by the fact that it belongs to some areas of law. The question is whether euthanasia is a common crime and therefore should be penalized or is a parallel of life's right, if so, does it protect the right of dignity? This question is related to human existential issues, the ontology and deontology, to individual and community rights. Euthanasia is a modern concept, but with a long-standing tradition of debate,as knowledge in justice, as practice in legitimacy.In nowadays, are always discussed ways of its decriminalization and in a further stage, its modes of legitimation.

Euthanasia is seen as a central point of debate, over the right to life as a fundamental human right, and the right of death was analyzed as a part of its supplementation in extremis. Euthanasia implicates the individual and society; is state and personal responsibility issue; Complicates life philosophy, theology, ethics, medicine and jurisprudence. Theoretical concepts exist in Albania, but there is a huge gap in law regarding euthanasia. It can be assumed that the lack of legislation for euthanasia, results in denying everyone's right to die in dignity. Sinani , 2012) If we refer to the cases handled by the European Court of Human Rights, we must emphasize that the right of life does not include the right to die. In Pretty v United Kingdom case, the Court noted that there was no violation of Article 2, when the state had refused to take over the investigations for a man who had assisted in the suicide of his wife, who suffered from an incurable disease, a disease which had affected all functions on her physical, but had not touched her intellectual capacity.

\section{Dilemma of Considering Euthanasia as a Criminal Offense or Not}

In general, there are various definitions of murder in Albanian and European criminal literature, but all conform to an essential element of unlawful deprivation of others life, intentionally or negligently. In this context the question is whether or not euthanasia is a punishable offense.In general, if we refer to the Albanian legislation, manslaughter, is considered the murder committed in the state of euthanasia, when a person, commits the murder, with the request and consent of the victim, or to end quickly severe pain caused by a serious and incurable illness, for mercy. Euthanasia murder case, has been discussed in the legal literature criminal world. In some countries, like the Netherlands, Belgium, Japan, etc., this kind of murder is not punishable by the Penal Code. (Elezi, 2007) There are many authors against this view and legal solution One of them is prof. Ismet Elezi, which, given the constitutional principle of protecting life, the right of life and humane principle that compels the doctor to fight to the end to save a life, is of the opinion that the murder committed in a state of euthanasia is punishable as a crime, based on article 76 or a murder in extenuating circumstances. (Article 82 of the Criminal Code of the Republic of Albania)

In Italian criminal law, euthanasia is punishable and perceived, as required murder. Guilty under criminal law is clear: "Whoever causes the death of a man with the request of the victim is punishable by 6-16 years." (Article 579 of the Italian Criminal Code) If we see components of the offense defined, they are the same as the crime of murder. Greek legislation provides a more lenient sentence, for everyone who help people who want to die, than for murders committed against the victim's will. (Shegani, Tafaj, 2011)

\subsection{Euthanasia - the act of will}

Euthanasia is, essentially, an act performed in order to accelerate death, for those patients suffering from an incurable disease and uncontrollable pain , physical and psychological, which require consistently and willfully, this act. There must be a significant number of claims, in order to be approved the act of euthanasia. Among them, we can mention the fact that the patient should pronounce his request repeatedly and in writing, in order to be extinguished any doubt about his lack of ability to think, doctor who follows the patient should consult with a second doctor to get his opinion on the health situation, to extinguish any doubts about depression on his patient cases etc. It is clear that in order to achieve an act of euthanasia, is not something ordinary and easily accessible to every kind of disease, therefore, the anxiety that comes from the idea of abuse legality of euthanasia, fades.

\section{Dignity - A Constitutional Principle in Relation to Euthanasia}

A special article is sanctioned in the Constitution of the Republic of Albania, about the principle of respecting and protecting human dignity. In its third Article is stipulated that: "Human dignity, rights and freedoms are the basis of this state, which is obliged to respect and protect them". Even in the Constitution preamble, protection of dignity and human 
personality explicitly mentioned as a commitment of the people. In Albanian constitutions history, the 1998 Constitution, was the first constitution which expressly sanctioned human dignity as a constitutional principle. The Constitution has listed other principles as well as specific personal rights and freedoms. However, respecting the dignity of the person serves as a basic interpretation, without which those rights can not be applied.(Omari, Anastasi, 2008, p 68)

In this context, $i$ think that if we face the constitutional principle of respect and affirmation of human dignity with the right to life, when a person does not want more life, but he wants to die and needs specialized assistance to implement the process painless, $i$ think that in this case should prevail principle of guaranteeing a dignified life and not a formal protection of the right to life. When a person with free act of his will, declares that it is impossible to afford immense suffering that come from an incurable disease, viewing the situation as a threat to his dignity, i think we should take into consideration the decision of the person. I want to emphasize that beforehand, must be conducted all tests to the person by the medical institutions specialized of physical-mental state of the person. In cases in which the person is skeptical or undecided about his decision, or when he does not understand the consequences of the decision, the request and his willingness should not be taken into consideration. I think that the situation must be examined objectively by the competent institutions, but the focus of every decision must be the respect of the human dignity. In respect of human dignity can be understood principles of indivisibility, inviolability _ and inalienable rights that underlie all the legal order. In respect of human dignity,it is set in the constitution the obligation of public authorities, in order to fulfill their duties to respect rights and fundamental freedoms and to contribute to their realization. When we talk about public government bodies, we note that there are not exceptions to the above obligation, ranging from the Parliament.This latter can not pass laws that contain such restrictions which go against human dignity.

It is important to mention that in connection with the principle of dignity, meaning and legal nature of this principle, there is some vacuum. Understanding this principle is not clarified concretely by the constitution. In Albania, there have been no definition nor from the Constitutional jurisprudence so far. This relatively long absence, risks making this principle in a solemn formula, which won't recognize any application, if will be left without content .Even the legal nature of this principle should be defined more precisely. It should be noted that the Constitution of Albanian, in contrast to other formulations in some constitutions of democratic countries, the clear position of the underlying constitutional principle, was given to human dignity. The principle of human dignity, is related with the catalog of human rights and fundamental freedoms.In particular, it is associated to the right to life, the protection of physical integrity, personal freedom etc..Just as human rights, the dignity is indivisible, inalienable, inviolable.In this way, everyone, holder of dignity, can not renounce of it, as public authorities can not deprive anyone from the right to human dignity and personality.( Omari, Anastasi, 2008, $p$ 69)

The question in this situation is: Can everyone, head of the right to life and dignity at the same time, decide on his own which of these two rights will be a priority and expect public authorities to respect his decision? Which of them will have an advantage in a situation where the person is not living with dignity (according to his assessment, but also a determination by doctors, of an incurable disease)? Should euthanasia be legitimized in such cases? Does Albania have the conditions to show contemporary standards in the application of euthanasia? These are the questions that come to my mind when I refer to Albanian social and legal context. What i found in Albanian jurisprudence, is that euthanasia and dignity principle are related to an element: the legal vacuum.For both concepts are no gaps in the legislation, so it is very difficult to make an objective analysis of their boundaries, determining which of them should prevail.In the Albanian context, we have numerous shortcomings and in today social realities, may seem hardy step legalization of euthanasialt is easy to legally pass the decriminalization of euthanasia procedure, but it is difficult to effectively manage it .

\subsection{Euthanasia versus human dignity}

The truth is that euthanasia has been a concern in recent decades and various European countries are trying not to penalize him or legalize, but that does not mean it has not existed earlier. Lawmakers are trying to find a common language for the right to life preserve the status of the most sacred right in the hierarchy. Thereby all human rights are built on respect, but at the same time allow the individual dignity even in critical moments, to prevent the use of the right to die for criminal purposes or benefits, such as the marketing of transplant bodies. Certainly, in countries where euthanasia is still considered to be murder to life, as a crime or as a random killing, many efforts have been made to prove the contrary. Numerous statistics have proven that in those countries where euthanasia is prohibited, its illegal practices, are increasingly larger. Arguing in this way, we can deduce that euthanasia can be an Albanian phenomenon. It is not surprising to think that a patient in coma may terminate food, or artificial breathing, take away control of devices through the approval of the family, thus bringing death, although this has no legal arrangement. This is nothing else but a 
form of illegal euthanasia.

There is no wonder that a patient afflicted with a terminal illness, refuses the treatment.In such a case, the doctor is obliged to obey his patient, consequently, is caused a passive euthanasia. The latter is more legally foreseen in the Code of Medical Deontology, although in contradiction with the Hippocratic Oath, which states that the fundamental task of the doctor is to protect the life of the patient.When we discuss about euthanasia, is said that it respects the human right to die in dignity.If dignity is a sense that everyone conceives with his eyes, then he remains a variable and a dignified life for someone, may not be dignified for someone else.

When a patient wants to die, the main reason is related to the lack of desire to live in serious condition physical and psychological.Most of, includes patients affected by degenerative disease with disabilities who can not move any limb of their body and the other internal organs were destroyed over time, until the loss of their vital functions.In such conditions, the life according to them, is not dignified and therefore is required euthanasia. Thus may also occur with other serious illness that can leave different consequences from externally and internally, but over all do not give hope for recovery.

\subsection{Arguments against euthanasia}

Euthanasia would not only be for people who are "terminally ill". Although the law may provide for a period of 6 months, doctors say that it is impossible to predict exactly when a patient will die. Some people diagnosed as terminally ill people do not die for years despite the diagnosis. Increasingly euthanasia activists define the incurable disease with phrases such as "hopeless disease", "desperate illness", physical or psychological pain, physical or mental incapacity, or an unacceptable quality of life, i.e. each person who has a suicidal impulse.

This problem of terms and inability to define in absolute the diseases those cause death, by those who do not do so hinders the application of euthanasia without negative effects.

Euthanasia can become a means of health care cost containment. Health insurance companies would benefit greatly from euthanasia if it would spread widely. Tools used for death by euthanasia cost about $\$ 40$, while to cure a disease it can be used even $\$ 40,000$. In the recent years it has been often discussed the problem of the high economic cost of treating illness, the latest apparatus of medical techniques often have a very high economic cost.

\section{Conclusions}

Euthanasia is a concept that involves almost all aspects: social, moral, religious, legal, financialand medical aspects. Its impact extends to all areas of life. Before I give my own attitude about this issue, i would appreciate reasonable, to emphasize that the topic is very delicate, because consequences of any decision would result decisive on the subject of euthanasia. If religion and a part of society, is categorically against, I think that the rest should explain patiently and consider even other legislations, in which euthanasia is not criminalized. Development stages of society, directly affects the willingness and predisposition of its members to address such social and legal phenomena. Constitutionalists positions or publications, or researchers and lawyers with deep knowledge of law, it is necessary to fill the legal vacuum regarding euthanasia. Our legislation has a highlighted gap about euthanasia, while incurable diseases, or loss of more important or vital functions, is a drama, not just for the patient who is "forced" to afford life in such conditions, but in all cases is a cost for the family and consequently also for society. What would be the gold median in such a situation?

I think our law should not penalize euthanasia, but should be set specific criteria and procedures in any case it would be applied. What is most important, consists in respect of human dignity. This is always an issue that should be left in the discretion of euthanasia subject. If a person chooses to have his life in priority, without violating his dignity, the government (legislative body) should create all the premises to respect his will, recognizing and guaranteeing the application of euthanasia through a specialised medical staff, notary, to certify his will and all social, financial and legal assistance that may complicate this process.If all specialists of all levels would have been harmonious and cooperative,i think euthanasia would only apply in cases absolutely necessary, without leaving room for abuse. In Albania euthanasia is still an issue that should have due attention, at least to be discussed, and then to make appropriate changes in the Albanian Penal Code.

\section{References}

The Constitution of the Republic of Albania

Omar L, Anastasi A, (2008) "Constitutional Law" ABC, Tirana 
European Convention on Human Rights

McCann and Others v United Kingdom (1995)

Ergi v Turkey (1998)

Gomien D, (2005) "Short Guide to the European Convention on Human Rights" Gent Grafik, Tirana

Commentary of Criminal Code of Albania (2006) Geer, Tirana

Sinani D, (2012) "Legal Definition of Death: Euthanasia", Naimi, Tirana

Pretty v United Kingdom (2002)

Elezi I (2007), "Criminal Law, part of the special" ERIK, Tirana

Criminal Code of the Republic of Albania

Criminal Code of the Republic of Italy

Counsel of Europe (2003) Universal Declaration of Human Rights

http://www.diritto.it/docs/32741-euthanasia-last-life-right-and-albanian-legislation?page=11

http://mapo.al/2013/01/eutanazia-e-drejta-per-te-vdekur-dhe-nje-propozim-juridik/

http://euthanasiagoat.blogspot.com/p/consequences-of-euthanasia.html 
